\title{
Zuiderzee is now called IJsselmeer*: Process-based Modeling
}

\author{
A. Dastgheib ${ }^{1}$ and J.A. Roelvink ${ }^{2}$ \\ ${ }^{1}$ UNESCO-IHE, PO Box 3015, 2601 DA Delft, The Netherlands, a.dastgheib@unesco-ihe.org; \\ ${ }^{2}$ UNESCO-IHE, PO Box 3015, 2601 DA Delft, The Netherlands, d.roelvink@,unesco-ihe.org, \\ Deltares, PO Box 177, 2600 MH Delft, the Netherlands, \\ Delft University of Technology, Delft, the Netherlands
}

* from Zuiderzeeballade

\begin{abstract}
Constructing a closure dam such as Afsluitdijk causes an instantaneous change in tidal wave propagation and flow field in the basin which triggers extensive morphological changes in the adjacent tidal basin. These morphological changes may continue for centuries before the whole system reaches a new "equilibrium" state, which is different from the "equilibrium" in case the closure would not have been done. In this paper we have used Delft3D to investigate the characteristics and time scale of the morphodynamic effects of construction of the Afsluitdijk. In this research we focused on tidal forces only. A schematized bathymetry with a uniform depth is used in the model with the land boundary of Waddenzee before the closure. A morphological simulation is carried out for 4000 years. Using this procedure ensures us that the morphological "equilibrium" state which is reached in this simulation is only due to the tidal forcing. In subsequent runs we have applied a closure after 1000, 2000 and 3000 years and continued the simulation while the closure dam was included in the model. The main outcome of this research is that as soon as the closure is applied the sediment transport regime of the basins changes from exporting to importing, which corresponds with the existing hypothesis based on measurements at Marsdiep.
\end{abstract}

\section{INTRODUCTION}

Closure dams in lowland countries such as The Netherlands are traditionally used to protect tidal inlets, rivers and estuaries from occasional storm surge events, and/or to provide possibilities to reclaim new land from the tidal basin area. Constructing a closure dam often causes an instantaneous change in tidal wave propagation and flow field in the basin which triggers extensive morphological changes in the adjacent tidal basin. These morphological changes may continue for centuries before the whole system reaches a new "equilibrium" state, which can be different from the "equilibrium" in case the closure would have not been done. (Figure 1).

After the construction of the Afsluitdijk in 1932, the tidal basin area in the Western Dutch Waddenzee decreased from around

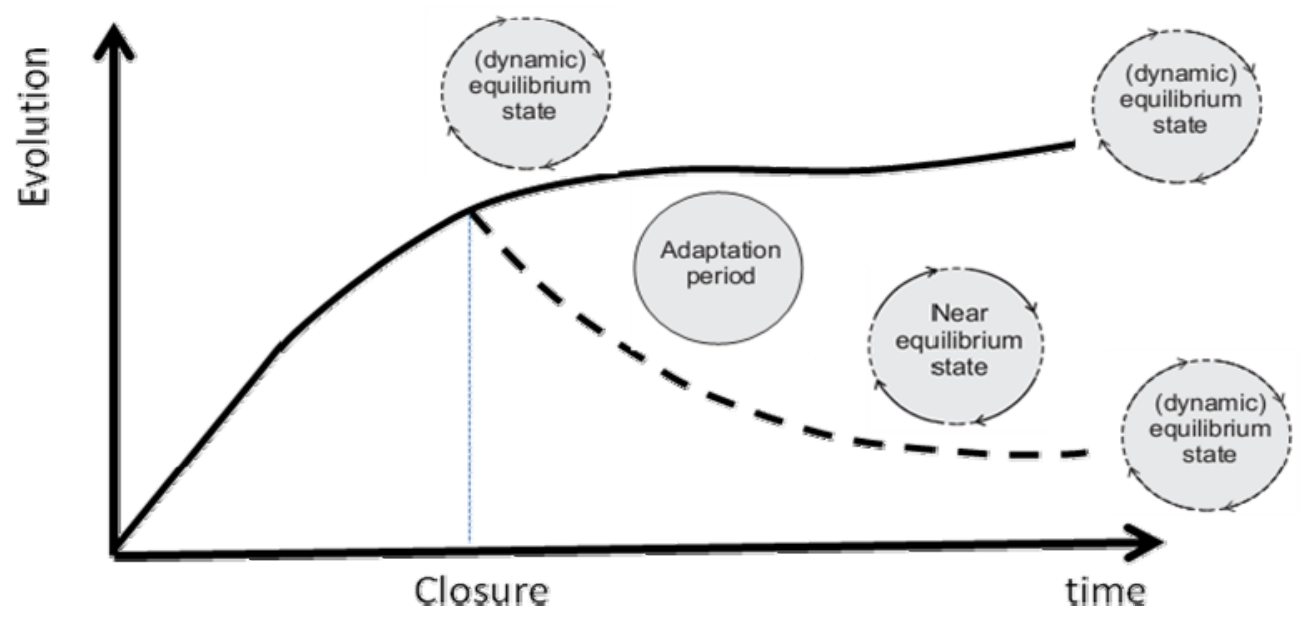

Figure 1. Description of the effect of closure dams (Stages of the evolution from Elias, 2003) 
$4000 \mathrm{Km} 2$ to $700 \mathrm{Km} 2$ and as it was predicted beforehand the tidal prism increase for about $26 \%$. This dramatic change is the main reason for the ongoing morphological changes in the new Dutch Waddenzee. Elias (2003) based on data and short-term simulations, extensively described the morphological changes due this closure, and suggested a conceptual model that explains the impact of the closure on the tidal basins.

In recent years advances in the knowledge of numerical modeling of the physical processes together with technological developments made it possible to use process-based models for mid- and long-term morphological simulations, and study the morphological behavior of the complex coastal systems such as tidal basins.(Hibma et al 2003, Van Leeuwen at al. 2003, Dastgheib et. al. 2008, Van der Wegen and Roelvink 2008, Van der Wegen et. al. 2008, Dissanayake et. al. 2009a,b). Using a process-based model and considering a realistic analogue approach (Roelvink and Reniers, 2012) we can select an important process in the morphological changes of tidal basins and give more insight into the effect of large human interventions such as closure dams on that specific process and consequently on the morphological behavior of the tidal basin.

\section{AIM OF STUDY}

In this study we have used a numerical process based model to investigate the characteristics and time scale of the morphodynamic effects of the construction of the Afsluitdijk and to determine the characteristics of the Dutch Waddenzee tidal basin without closure dam only due to tidal forcing.

\section{DESCRIPTION OF THE MODEL}

The model which is used in this study is the $2 \mathrm{DH}$ version of the Delft3D model, described in Lesser et al (2004) in detail. Basically the governing equation of the same model is integrated over depth. This model is a finite difference-scheme model which solves the momentum and continuity equations on a curvilinear grid with a robust drying and flooding scheme. For this exploratory study, the simplest possible physics (depth-averaged shallow water equations, simple transport formula) are applied. In this study the empirical relation of Engelund-Hansen is used for sediment transport.

Following Roelvink (2006) we have used the so called online approach. In this approach the flow, sediment transport and bedlevel updating run with the same (small) time steps (Lesser et al, 2004, Roelvink, 2006). Since the morphologic changes are calculated simultaneously with the other modules the coupling errors are minimized. But, as described in Lesser et al (2004), because this approach does not consider the difference between the flow and morphological time step, a 'morphological factor' to increase the depth changes rate by a constant factor (n) should be applied (Roelvink, 2006). So after a simulation of one tidal cycle in fact the morphological changes in $\mathrm{n}$ tidal cycle are modeled.

\section{MODEL SETUP}

\section{Model Domain}

A model for the Waddenzee before closure is set up. The landboundary of the model is determined using historical maps together with the borders of Dutch new municipalities. In this study our interest is to set up a model with a reasonable computational time that can simulate long-term $(\sim 4000$ years $)$ morphological changes. The grid we generated is a compromise between enough resolution in the inlets (at least 10 at the gorge ) and having as few cells as possible. In this study the average spacing between grid lines inside the basins is about $350 \mathrm{~m}$. The grid cells are smaller inside the basins and they are much bigger at the offshore boundary. The grid mesh covers only the area under the high water and the other parts of the barrier islands are excluded from the model. Figure 2 shows the domain and the computational grid of the model.
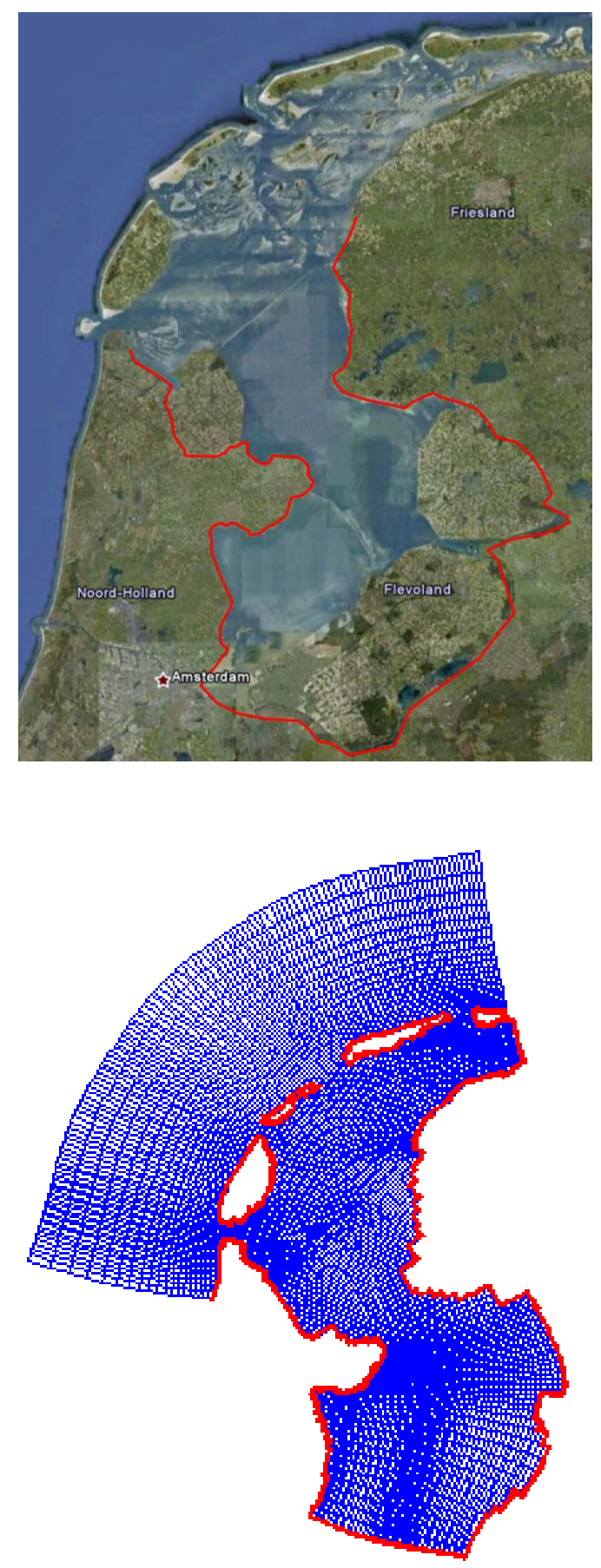

Figure 2. land boundary and the computational grid of the model 


\section{Forcing}

The only hydrodynamic force which is chosen for the simulations in this study is the tidal forcing and other forces such as wave and wind are not included in the simulations.

In order to determine the boundary conditions of this local model, a calibrated model for the vertical tide in the North Sea, called 'ZUNO', is used.

Referring to Van de Kreeke and Robaczewska (1993), we neglect the spring neap cycle and consider the dominant forcing by M2 and over-tides. Therefore the ZUNO model is run with the forcing boundary conditions of M2, M4 and M6 until a periodic solution was reached. During this run the tidal level variations at the boundaries of local model are recorded.

From the results of ZUNO model the recorded tidal variations at local model boundaries are analyzed and M2, M4 and M6 are extracted for these boundaries. These components are used to form boundary conditions for the local model.

The boundaries for the local model consist of 3 boundaries: one boundary at the sea side and two other lateral boundaries. The sea side boundary is chosen to be a water level boundary, while the lateral boundaries are Neumann boundaries, where the alongshore water level gradient is prescribed (Roelvink and Walstra, 2004).

\section{Initial Bathymetry}

The initial bathymetry which is used in the simulations of this study is a flat bathymetry inside the basins without any kind of ebb-tidal delta outside the inlets. Therefore the model simulates the mechanism of building and changing the ebb-tidal delta outside the basin and channel and shoal patterns inside based on the applied forces and the available sediment. In this case the uniform depth of this flat bathymetry is equal to average depth of the basins.

\section{Scenario of simulations}

In this study a morphological simulation is carried out for 4000 years including the whole domain (Waddenzee together with the Zuiderzee) to achieve a reasonable computational time a MorFac of 300 is applied. Using this procedure ensures us that the morphological "equilibrium" state which was reached in this simulation is only due to the tidal forcing. To investigate the effect of the morphological conidian at the time of closure, in subsequent runs we have applied the closure after 0, 1000, 2000, 3000 and 4000 years and continued the simulation including the closure dam (the same model domain excluding the Zuiderzee).

\section{RESULTS AND DISCUSSIONS}

\section{Morphological evolutions}

Figure 3. shows an example of the morphological evolution with and without the closure, in this figure the resulting bathymetry of the whole domain in year 2000 is shown. It is clear that in the first 2000 years the channels in Vlie and especially Marsdiep are penetrating into the Zuiderzee and this procedure continues for the next 2000 years if there is no Afsluitdijk, the main channels of Marsdiep is connected to the Zuiderzee and has a south easterly direction. However in the case in which the closure is applied at the year of 2000 the main channel in Marsdiep rotates towards the east and the connection between Vlie and Marsdiep is cut. The areas closer to the closure dam is silted up and some flat areas are developed in that area.

\section{Instantaneous changes due to closure}

At each closure time we carried out two hydrodynamic/sediment Transport model and compared the discharge of water and sediment passing though the Texel inlet and the water level at Den Helder station before and after the closure, Figure 4 shows the outcome of this comparison for closure at 1000 years and 3000 years. Over all we can observe some tidal asymmetry in the flood and considerable reduction in ebb-Sediment transport due to the closure. Therefore we can conclude that before the closure Texel is ebb-dominant both for tidal-flow and tidal transport, thus, exporting sediment. After the closure Texel is still ebb-dominant for tidal-flow but flooddominant for tidal transport and importing sediment, this result is in agreement with Elias et. al (2004) descriptions of the effect of the construction of the closure dam on Texel inlet. Also we can see that the tidal range increases by about $20 \%$ which is comparable with what happened in reality.
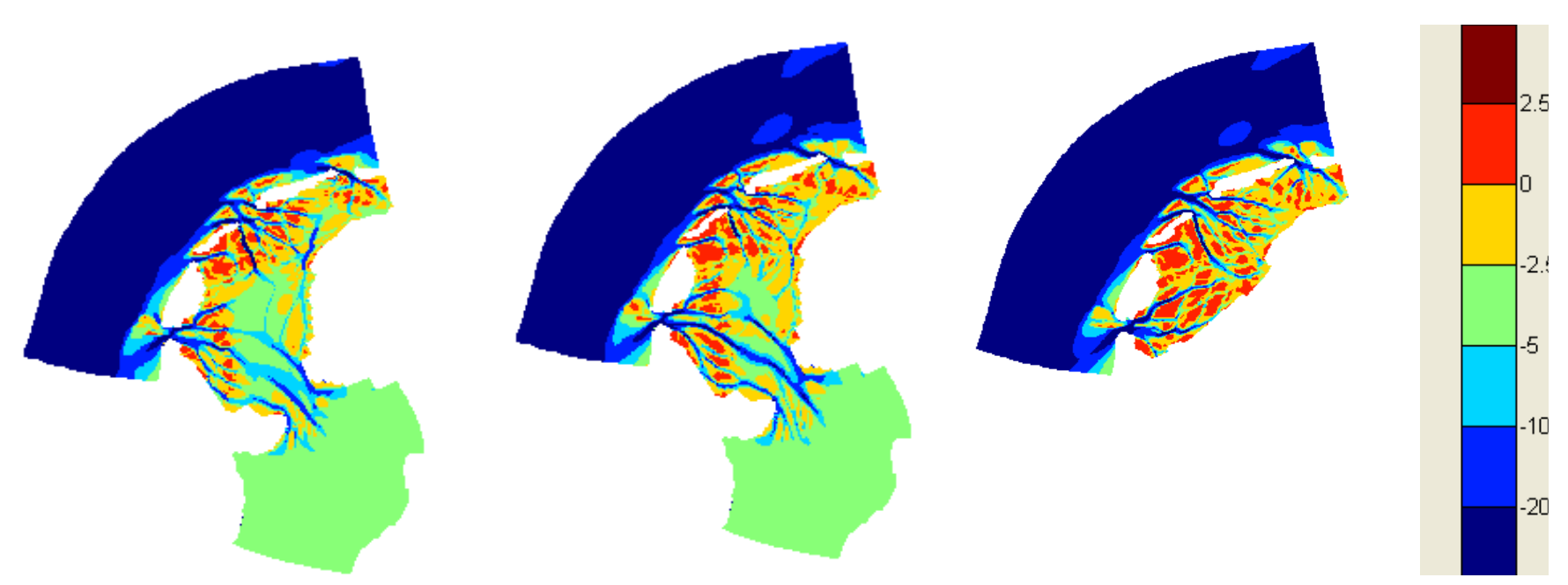

Figure 3. From left to right :Resulting bathymetry in year 2000, in year 4000 without the closure, and in year 4000 with the closure dam included in year 2000 

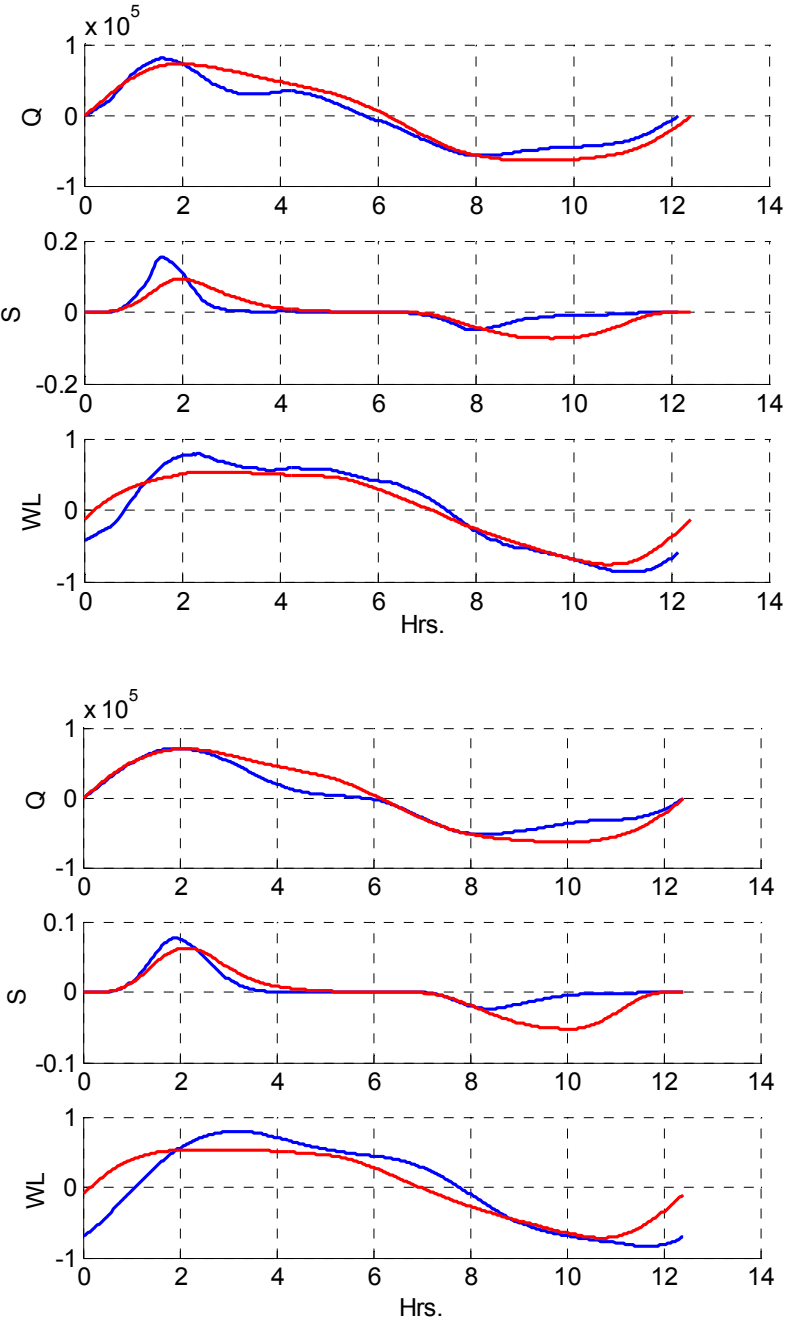

Figure 4. Discharge, Sediment Transport and water level in Texel inlet before (red) and after (blue) the closure at year 1000 (top) and 3000 (bottom)
This change from being ebb-dominant to being flood dominant for tidal transport, changes the regime of the tidal basins in Waddenzee from an exporting system to an importing system. Figure 5 shows the sediment exchange between North Sea and Waddenzee through Texel and Vlie inlets in 4000 years morphological simulation without the closure together with the change of the import export regime due to the closure at different times.

\section{CONCLUSIONS}

The main conclusions can be summarized as follows:

- Even considering tidal forcing only it is possible to show the change in import/export regime of Texel (Waddenzee)

- After the closure Texel is ebb-dominant for tidal flow but becomes flood-dominant for tidal transport.

\section{REFERENCES}

Dastgheib, A., Roelvink, J.A., Wang, Z.B., 2008. Long-term process-based morphological modelling of the Marsdiep Tidal Basin, Marine Geology, 256, 90-100.

Dissanayake, D.M.P.K., Roelvink, J.A., Ranasinghe, J.A., 2009a. Process-based approach on tidal inlet evolution - Part II, Proc. International Conference in Ocean Engineering, Chennai, India. CD Rom.

Dissanayake, D.M.P.K., Roelvink, J.A., Van der Wegen, M., 2009b. Modelled channel pattern in a schematised tidal inlet. Coastal Engineering 59, 1069 - 1083

Elias, E. P. L., Stive, M. J. F., Bonekamp, J. G. and Cleveringa, J. 2003 Tidal inlet dynamics in response to human intervention Coastal Engineering Journal, 45(4), 629-658.

Elias, E.P.L.; Stive, M.J.F., and Roelvink, J.A., 2004. Impact of back-barrier changes on ebb-tidal delta evolution. Journal of Coastal Research SI(42).

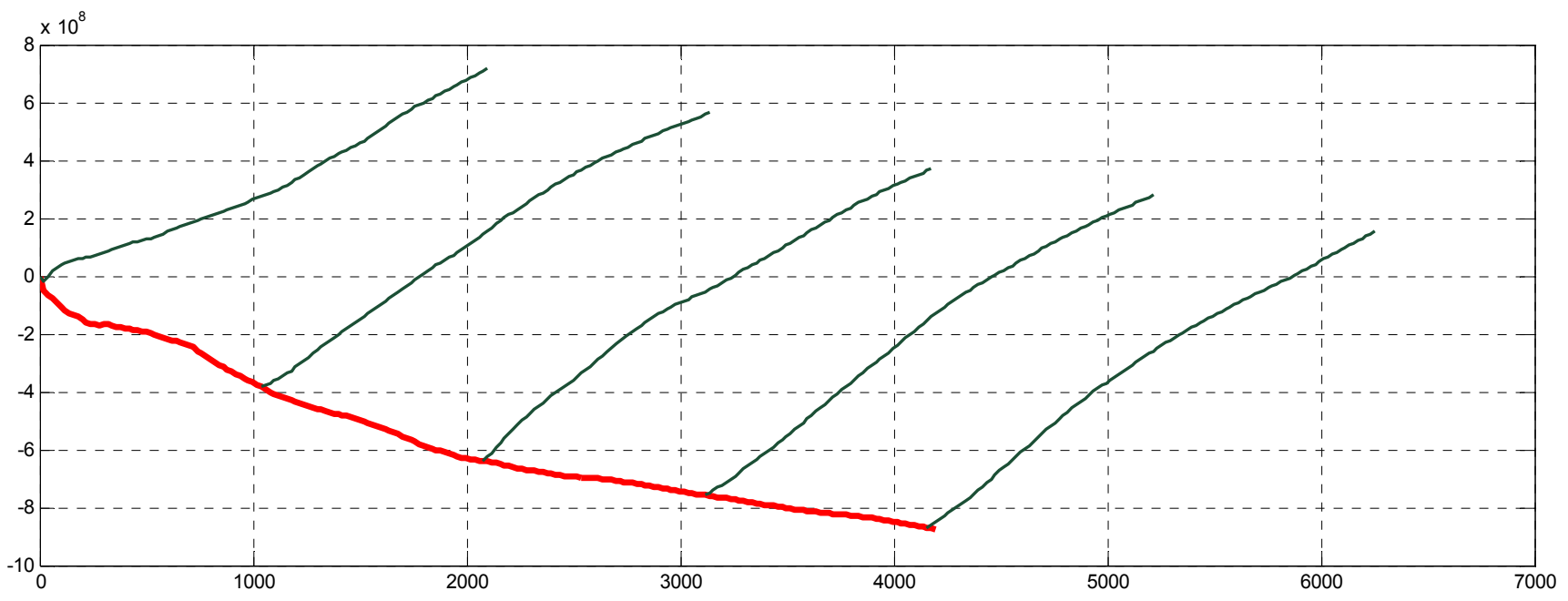

Figure 5. Sediment Exchange between North Sea and Waddenzee in 4000 years morphological simulation and the change of the import export regime due to the closure at different times, (+:import, - : export) 
Hibma, A., De Vriend, H. J. and Stive, M. J. F. 2003. Numerical modeling of shoal pattern formation in well-mixed elongated estuaries Estuarine, Coastal and Shelf Science, 57, 981-991.

Lesser, G. R., Roelvink, J. A., Van Kester, J. A. T. M. and Stelling, G. S. 2004. Development and validation of a threedimensional model. Coastal Engineering, 51, 883-915.

Roelvink and Reniers, 2012. A guide to modeling coastal morphology. World Scientific Publishing co.

Roelvink, J.A. 2006. Coastal morphodynamic evolution techniques, Coastal Engineering 53, pp. 277-287.

Roelvink, J.A., Walstra, D.J., 2004. Keeping it simple by using complex models, Advances in Hydroscience and Engineering, Volume V1, 1-11

Van der Kreeke, J., Robaczewska, K., 1993. Tide-induced residual transport of coarse sediment; application to the Ems estuary. Netherlands Journal of Sea Research 31, 209-220.

Van der Wegen, M., and J. A. Roelvink 2008, Long-term morphodynamic evolution of a tidal embayment using a twodimensional, process-based model, Journal of Geophysical Research Volume 113, Issue 3, 8 March 2008, Article number C03016

Van der Wegen, M., Z.B. Wang, H.H.G. Savenije and J.A. Roelvink 2008, Long-term morphodynamic evolution and energy dissipation in a coastal plain, tidal embayment, Journal of Geophysical Research Volume 113, Issue 3, 24, Article number F03001

Van Leeuwen, S.M., Van Der Vegt, M., De Swart, H.E., 2003. Morphodynamic of ebb-tidal deltas: a model approach. Estuarine, Coastal and Shelf Science 57, 899-907. 